\title{
Poder e Liderança: as contribuições de Maquiavel, Gramsci, Hayek e Foucault
}

\author{
Maria Cristina Sanches Amorim 1 \\ Regina Helena Martins Perez ${ }^{2}$
}

\section{Resumo}

Liderança é um campo amplo no universo do comportamento organizacional. Os conceitos são problemáticos, no sentido da delimitação do objeto de estudo, ainda controversa. A maior parte da literatura origina-se na psicologia social, enquanto que a teoria política é pouco explorada na construção dos conceitos. Contribuições dos autores oriundos da psicologia social, quando "traduzidas" para o grande público disseminaram o surgimento de estereótipos e fórmulas, marcados pelo viés do chamado politicamente correto e pela despolitização do tema. Objetivo: mostrar que a ciência política pode ampliar o debate, propondo o estudo das relações entre poder e liderança nas organizações. Metodologia: revisão bibliográfica multidisciplinar, compatível com o ensaio teórico. Conclusões: a ciência política permite definir liderança como exercício de poder nas organizações, contornando o problema conceitual do tema; poder não tem conotação negativa ou positiva, tais juízos respeitam as formas e objetivos do poder; exercer o poder é uma contingência da liderança.

Palavras-chave: Comportamento organizacional. Liderança. Poder.

\section{Introdução}

A literatura sobre liderança é constituída principalmente pelas contribuições da psicologia e, em segundo plano, da sociologia (ROBBINS, 2005). Há pouca influência da ciência política e esta, por sua vez, quando utilizada, o é em sentido restrito, pois o poder é considerado apenas na acepção negativa de opressão e conflito. O objetivo do artigo é contribuir para a discussão sobre o tema liderança, à luz da ciência política, tendo como referência os "clássicos" da política, Maquiavel, Gramsci, Hayek e Foucault.

\footnotetext{
${ }^{1}$ Doutora em Ciências Sociais. Economista. Professora titular de departamento de economia e do programa de pós-graduação em administração da PUC/SP. Endereço: Rua Ministro Godoy, $9694^{\circ}$ andar, bloco A, sala 4E04, CEP: 05.015-000. São Paulo - SP - Brasil. E-mail: cristina.amorim@attglobal.net.

${ }^{2}$ Doutora em Ciência Sociais pela PUC/SP. Psicóloga. Professora da Escola Superior de Propaganda e Marketing - ESPM. Endereço: Rua Ministro Godoy, $9694^{\circ}$ andar, bloco A, salal 4E04, CEP: 05.015-000. São Paulo-SP - Brasil.E-mail:mhm1@uol.com.br.
} 
O foco escolhido é a liderança associada ao posicionamento do indivíduo na hierarquia, a chamada liderança formal, ainda que na acepção de Foucault, influenciar pessoas independentemente do cargo também seja uma forma de exercer o poder.

Este artigo nasceu dentro do grupo de pesquisa sobre organizações e sistemas de saúde, constituído por professores, mestrandos, doutorando e alunos de especialização. Em dado momento, foi necessário agregar a pesquisa ao estudo sobre liderança, em virtude da necessidade de compreender, no nível do desempenho das pessoas, as diferenças entre as organizações de saúde. No primeiro estágio da pesquisa, percebeu-se a existência de interesses divergentes em todos os elos da cadeia produtiva. No segundo, foram estudadas as relações entre interesses organizados corporativamente e poder, desaguando na análise das ações dos indivíduos como agentes dos blocos de interesse. Para entender as questões colocadas pelo segundo estágio da pesquisa, foi necessário estudar liderança e poder nas organizações - o artigo resulta dessa reflexão sobre a teoria da liderança e a teoria política.

A produção teórica sobre liderança é ampla (BERGAMINI, 2004), as chamadas "escolas", organizadas em torno de características e papéis são sobejamente conhecidas e, por esse motivo, não se apresenta exaustiva revisão bibliográfica dos títulos e "escolas", mas privilegia-se o menos explorado, as contribuições vindas da ciência política.

Enquanto a academia e os pesquisadores têm importantes e pertinentes reticências teóricas, os executivos consomem vorazmente a literatura voltada para o grande público que, muitas vezes, é de qualidade discutível. O discurso hegemônico das revistas de negócio voltadas para o grande público é marcado pelo que se supõe politicamente correto. Nos limites desse artigo, o politicamente correto significa a assunção de discursos esvaziados dos conteúdos originais, utilizados para evitar conflitos com o público, na tentativa de despolitizar os debates. Em outros termos, no lugar da imprescindível discussão sobre ética e moral nas organizações surgem os clichês recomendando condutas quanto aos relacionamentos entre gêneros, às religióes, aos subordinados, às características étnicas e particularmente, quanto ao poder.

Na literatura para o grande público, a despolitização resulta na caracterização do líder ideal como um indivíduo virtuoso, acima do bem e do mal. O estudo da política o convida a repolitizar o debate, sugerindo que se o poder se expressa também por meio da liderança, é conveniente investigar as relações entre o primeiro e a segunda. 


\section{Liderança}

A psicologia organizacional, pioneira no estudo sobre liderança, deu notáveis contribuições ao debate e, ao mesmo tempo, propiciou abordagens dicotômicas, demarcando a discussão entre a corrente behaviorista e a fenomenológica, sugerindo que uma das correntes é correta e a outra, errada. Bergamini (1994, p. 84), provavelmente a autora nacional mais lida, adverte o leitor sobre as diferenças irreconciliáveis entre as duas correntes, de sorte que "[...] não se pode aceitar a ambas correntes ao mesmo tempo para explicar um mesmo tipo de comportamento". A autora prossegue na demarcação entre os dois campos conceituais ao citar Milhoan e Forisha, autores de

[...] uma obra de divulgação em psicologia, não muito sofisticada, mas escrita dentro de aceitáveis critérios científicos, propõe [...] a diferença entre a visão comportamental e fenomenológica do ser humano: a orientação comportamentalista considera o homem como um organismo passivo, governado pelos estímulos fornecidos pelo meio ambiente; o homem pode ser manipulado, o que significa que seu comportamento pode ser controlado. [...] a corrente fenomenológica considera o homem como fonte de todos os seus atos, [...] é essencialmente livre para fazer escolhas em cada situação (BERGAMINI,1994, p. 85).

Desde as críticas do indutivismo por autores como Popper (1980), Kuhn (2003) e Lakatos (1983), a ciência não mais se arvora em verdade única. As contribuições da teoria do caos, por sua vez, incumbiram-se não só de aprofundar as críticas, como de mostrar que, se não há a verdade absoluta, então, a regra passa a ser a complementaridade entre os saberes (PRIGOGINI; STENGERS, 1991). Se concordarmos com os autores da teoria do caos e da complexidade, temos mais um motivo para olhar a liderança por outros enfoques, como por exemplo, o do poder, ancorando-nos na teoria política.

Percebe-se na citação da dupla de autores Milhoan e Forisha (apud BERGAMINI,1994), de sorte repetida exaustivamente na literatura, um evidente julgamento das duas teorias. Dado que na sociedade ocidental, fortemente marcada pela cultura liberal (como se verá adiante, com Hayek), controlar ou ser controlado são categorias negativas, o behaviorismo e tudo que deriva dele, transformou-se em condutas pejorativas: arcaicas, 
equivocadas e, até mesmo, perversas. Por isso a literatura sobre liderança ter fundado dois tipos clássicos de executivos. De um lado, o chefe, associado à administração científica no início do Século XX e ao behaviorismo, talhado para gerir processos, de outro, o líder, ligado à corrente da escola de Recursos Humanos e ao comportamentalismo, voltado para funções menos estruturadas (na vertente popular, é o ser carismático, visionário e, principalmente, um exemplo de virtudes a serviço dos interesses do grupo).

Distante da economia e da política, as teorias sobre Recursos Humanos absorveram as contradições estruturais do capitalismo na forma de posicionamento militante, caracterizado pelo dilema quanto ao papel dos estudos sobre comportamento organizacional. Ou se produzia saberes prócapitais, procurando aumentar a produtividade do trabalho, ou se tratava da produção intelectual para a defesa do trabalhador, protegendo-o da lógica capitalista da busca pelo lucro crescente.

Com relação a tal debate, as transformações no mundo do trabalho em curso desde os anos de 1980 incumbiram-se de solapar a pertinência do dilema. O aumento da precariedade das relações de trabalho, diante da qual o emprego formal é quase um privilégio (DOWBOR, 2002), ou, a ideologia dominante da globalização segundo a qual os benefícios conquistados pelos trabalhadores são resquícios de administração paternalista (TODD, 1999) cumpriram a função de inutilizar o posicionamento dito "pró-trabalhador". A popularidade da expressão "colaboradores" para designar o que já foi denominado de força de trabalho, trabalhadores ou funcionários evidencia a obsolescência do velho dilema e também a vitória do politicamente correto.

Ao mesmo tempo, na medida em que os trabalhadores foram deixando as funções repetitivas (cada vez mais executadas por máquinas eletrônicas), em prol de tarefas criativas, as organizações foram obrigadas a desenvolver outros instrumentos de controle, muito mais persuasivos do que opressivos. Ou seja, embora a defesa dos interesses do trabalhador tenha se esvaziado como prática e discurso, dada a emergência do trabalhador semântico (DANTAS, 1996), as organizações são levadas a práticas de controle da produtividade que, em algum grau, considere os interesses dos primeiros. O processo de adaptação das formas gerenciais aos trabalhadores do conhecimento é cheio de avanços e retrocessos, contradições e superações. A literatura sobre liderança voltada para o grande público no mundo dos negócios expressa esse processo: trata de refrear o poder do líder sugerindo 
que "sirva ao grupo", ao mesmo tempo em que procura formas politicamente corretas de motivar e controlar os "colaboradores".

A vertente comportamentalista, que influenciou a teoria dos traços, começou a organizar um campo teórico para a pesquisa. Fruto da ciência hegemônica de sua época, o positivismo, utilizou como método as análises de correlação - e as correlações entre traços do líder e desempenho do grupo não foram significativas. $\mathrm{O}$ método de pesquisa utilizado estava marcado pelo apriorismo, velho problema do indutivismo: partia-se de uma noção, a priori de líder, para definir liderança. Em grande medida, o apriorismo não foi resolvido também pela corrente fenomenológica, daí a definição problemática do conceito de liderança, aludida anteriormente. Além disso, o método da análise de correlação, típico dos sistemas estruturados, jamais se prestou ao objeto de análise, semiestruturado (MATUS, 1995) ou autopoiético (MATURANA; VARELA, 1997).

A escola das teorias contingenciais trouxe à tona a importância do contexto, da cultura organizacional, do tipo de tarefa e do tipo do grupo para a compreensão do fenômeno da liderança das organizações. Contribuiu também para o fim da crença na existência do líder ideal, cujo padrão possa ser decodificado e replicado. Entre os mais lidos, cita-se o modelo de Fiedler (ROBBINS, 2005), de Hersey e Blanchard (1986), das trocas entre líder e liderados, e de Robert House (ROBBINS, 2005).

A despeito das divergências entre as origens teóricas das escolas sobre liderança, há um consenso, por exaustão, de que a liderança envolve um quantun de características de personalidade, outro da adequação dessas ao contexto, ao grupo e ao tipo de tarefa. Esse é o motivo pelo qual há sempre a pretensão de uma taxonomia da liderança, seja por traços de personalidade, seja por inclinação à tarefa ou às pessoas, seja ainda pelo grau de maturidade do grupo liderado, entre outras classificações. A funcionalidade da classificação em tese repousaria nas necessidades de recrutamento, seleção e treinamento de pessoas. Ao abordar a liderança na perspectiva do poder, tais classificações não têm pertinência, como se verá com Foucault (1995) e Maquiavel (1973).

A emergência do contexto, do tipo de tarefa e do grupo como elementos de análise das teorias da liderança muda o foco do indivíduo para um sujeito indeterminado. Tal movimento pode ser compreendido na dinâmica da economia e da sociedade nas últimas décadas do Século XX e início do Século XXI, cujas formas de organizações capitalistas são simultaneamente produtoras 
e produzidas pela cultura pós-moderna. No mundo de substituição da mão de obra do trabalho repetitivo pelas máquinas informatizadas, as formas de obtenção de produtividade são diferentes daquelas utilizadas pela administração científica (HELOANI, 2003). Motivação, coaching, time, entre outras são expressões características do desenvolvimento gerencial de quadros profissionais ultra-qualificados, da parcela trabalhadora no emprego formal, com mobilidade quase tão grande quanto a do capital globalizado. Essa elite ocupada do trabalho semântico e criativo ou não se adapta, ou prescinde dos antigos instrumentos de controle (DANTAS, 1996).

Identifica-se, pois, a contemporaneidade das teorias contingenciais da liderança como a produção na fronteira do conhecimento, na acepção dada por Popper (1980). Porém - e na ciência parcial do Século XXI há sempre um porém - a emergência do sujeito coletivo provocou um enfraquecimento das discussões sobre o poder como uma das funções do líder, como de resto, em toda a organização (TODD, 1999). Obra muito popular, inclusive nos bancos universitários, o livro de Kouzes e Posner (2003) afirma que a liderança está ao alcance de todos e recomenda cinco regras básicas para seu exercício, nenhuma respeita o poder.

No nível teórico, é bastante plausível admitir a liderança oscilando entre traços pessoais, estilos, motivação, organização das decisões e visão de futuro, como elementos não excludentes. Os muito manuais, ainda que simplifiquem ilegitimamente o complexo, têm contribuições positivas em, no mínimo, um dos campos constitutivos do mundo chamado liderança.

A ciência política pode dar pistas para outras faces da liderança, explorando temas como poder, contrapoder, boicote, disciplina, controle, imagem, adequação entre fins e meios, entre outros. Antes que o clichê do dito politicamente correto se manifeste, é importante lembrar que, na tradição de Maquiavel, é conveniente saber discernir a realidade do líder nas organizações, da idealização do líder. As questões levantadas pelo exercício do poder nas organizações levam, por sua vez, à reflexão sobre a ética e conduta moral do líder.

\section{Poder e Liderança nas Organizações}

Um conceito determina e restringe um significado, na tentativa de diminuir as armadilhas semânticas da linguagem, para o bem da pesquisa 
científica. Se são demasiadamente restritos, podem não abarcar o fenômeno em tela, se são demasiadamente amplos, perdem-no. Um conceito abre ou fecha possibilidades de interpretação e, principalmente, de ação (MATURANA; VARELLA, 1997). O foco de uma pesquisa é baliza adequada para determinar o grau de amplitude de um conceito.

O histórico das pesquisas sobre liderança mostra o quanto os estudiosos estiveram à procura de traços ou comportamentos universais; esse objetivo pode tê-los levado a ampliar mais e mais o conceito de liderança, explodindoo a ponto de torná-lo problemático. Fenômeno semelhante acontece com os conceitos de estratégia, globalização, entre outros.

Os conceitos de liderança relacionados à administração científica apresentavam-na como uma das funções gerenciais, ao lado de planejamento, organização e controle. A função liderar constituía-se em dirigir, coordenar, motivar e resolver conflitos. Há ainda o reconhecimento das atividades simbólicas e de capacitação dos liderados (ROBBINS, 2005). Na administração científica destacam-se as expressões dirigir e coordenar e, também, a existência da função controlar, ou seja, marcando o quanto liderar é diferente de controlar. Em um mundo dividido entre colarinhos brancos e uniformes azuis do chão de fábrica, o controle era tarefa de chefias intermediárias e, portanto, sem nível decisório, no qual estavam os líderes, formalmente imbuídos do poder do cargo.

$\mathrm{Na}$ medida em que avança-se pelas correntes contingenciais, o conceito sofre duas modificações importantes: descola-se da hierarquia ou posição formal, e o verbo mais usual para caracterizar a função é influenciar, ao invés de dirigir ou coordenar (TANNEBAUM; WESCHLER; MASSARIK; JACOBS; KATZ; KAHN; ROUCH; BEHLING; apud BERGAMINI, 1994). John Kotter (1990) acentua a diferença entre administrar e liderar, propondo que a primeira respeita ao controle dos processos rotineiros, enquanto que a segunda implica em gerir a mudança.

Ao definir-se a liderança informal e, portanto, ao desconectá-la do cargo, não cabe mais a expressão dirigir, substituída pelo verbo influenciar. Nesse ponto, a ideia de poder se alija do exercício da liderança e o líder, presumivelmente, está liberado de seus jogos e disputas, livre para ser o guia visionário e generoso de seu grupo. Não se imagina proibido ao líder ser visionário e generoso, mas considera-se discutível que seja apenas bom. Recuperando Jung (1987), o que o líder faz da sua sombra? 
A expressão influenciar, por sua vez, cabe a vários outros campos da teoria da administração: a motivação, o empreendedorismo, a criatividade, a gestão do conhecimento - todas essas áreas de estudo comportam a importância da influência de uns sobre outros. O operário motivado pode influenciar outros a desempenhar o trabalho com o mesmo ímpeto; o indivíduo empreendedor e criativo pode influenciar pessoas; o professor pode criar um ambiente propício ao aprendizado e levar alunos à automotivação. Então, qual a especificidade do conceito de liderança quando calcado na capacidade de uns influenciarem e outros se deixarem influenciar? Verbo capcioso, influenciar associado à liderança levou, na literatura para o grande público, a uma ideia no mínimo contraditória, de que todos os indivíduos, independentemente do cargo e características pessoais, podem ser líderes, simultaneamente. Se liderar só se define pela existência de liderados, como conseguir que todos sejam líderes? A tese de que todos podem ser líderes provavelmente confunde no mesmo campo conceitual, temas correlatos, mas não sinônimos, tais como motivação e empreendedorismo.

Quanto à definição proposta por Kotter (1990), que divide as atividades de gerenciamento e liderança, no mundo do downsize, como garantir a posição de profissionais escalados exclusivamente para pensar o futuro, excetuando o minúsculo grupo de presidentes e vices de grandes companhias? $\mathrm{Ou}$, visto do outro ângulo, ainda há espaço para profissionais limitados ao cumprimento de regras e protocolos, como se não fossem seres pensantes dotados de subjetividade?

Qual a contribuição da ciência política para o debate em torno do liderar? Propõe-se explorar o tema partindo-se do entendimento da liderança como uma das formas de poder nas organizações. Restringe-se o fenômeno da liderança ao exercício de cargo de direção, esta compreendida como a existência de subordinados formais e, ao mesmo tempo, de superiores hierárquicos.

O que é poder? Não há resposta única, mas é possível organizar autores em dois grandes grupos: aqueles que o definem como categoria social negativa, e os que o enxergam como positividade. O senso comum apreende o poder apenas em sua negatividade. Essa visão de mundo origina-se no pensamento liberal, doutrina filosófica e política do Século XVIII. Na época, ser liberal significava defender a liberdade religiosa, a república e os direitos universais do cidadão, "promulgados" pela Revolução Francesa. Na esfera política, o liberalismo inspirava partidos burgueses contra a aristocracia 
conservadora. Na esfera filosófica, imperava o individualismo dos pensadores humanistas - o homem no centro da vida, em oposição às visões teocêntricas. No final do Século XIX surge o neoliberalismo, quando contendas religiosas e relativas à construção de Estados democráticos já estavam superadas na Europa e nos EUA (ainda que muitas monarquias fossem preservadas, mas sob o poder de constituições e parlamentos). O neoliberalismo preserva o traço filosófico do individualismo, propondo a liberdade individual como bem supremo e tudo que ameaçá-la, ameaça a integridade e a felicidade do homem.

Hayek (1977), prêmio Nobel de economia e grande expoente do neoliberalismo no Século XX, mantém a tradição liberal ao voltar-se contra a maior ameaça sobre a liberdade do indivíduo: o Estado. O regime político ideal é a democracia, e só viceja onde houver homens livres, isto é, quando o interesse individual determinar as ações do governo. Na célebre obra O caminho da servidão (1977), expressões como "bem comum" são consideradas engodos, formas de opressão para justificar o poder de poucos. E nas sociedades capitalistas meritocráticas, os piores chegam ao poder, pois lhes faltaram competências para triunfar como seres empreendedores. Na perspectiva de Hayek (1977), poder é controlar pessoas, suprimindo-lhes as liberdades individuais, impedindo-as de viver da única forma legítima: a competição pelas melhores oportunidades.

Na perspectiva liberal de Hayek (1977), poder é sinônimo de submissão ao jugo de párias, sendo ignóbil tanto subjugar, quanto se deixar dominar. E o poder, quanto maior, propicia maiores possibilidades de corrupção, pois sua finalidade última é o acúmulo de riqueza pessoal ou de grupos.

A visão de mundo liberal é hegemônica nas sociedades capitalistas e, consequentemente, nas organizações. São valores contraditórios, pois na mesma proporção em que alicerçam o grau necessário de competição entre os trabalhadores, boicotam o espírito de equipe, a solidariedade e, fundamentalmente, a capacidade de assumir os objetivos organizacionais. $\mathrm{Na}$ maioria das vezes, os sistemas de remuneração e promoção estão estruturados no desempenho individual, reforçando a cultura liberal.

As críticas ao pensamento liberal e ao individualismo foram apresentadas desde o Século XVIII. Hegel (apud ARANTES, 1988) qualificava-os de equivocados na origem: a liberdade só se configura como necessidade na vida coletiva - o ermitão perdido no meio do deserto não se defronta com o problema. Portanto, é no equilíbrio entre necessidades individuais e de 
pertencer ao grupo que a liberdade se define. Não há indivíduo livre em sociedade opressora, há, sim, o bem comum legitimado pela necessidade da construção de uma sociedade justa e tolerante, governada pelo Estado, árbitro supremo capaz de equilibrar as demandas do espírito e da matéria, do grupo e do indivíduo. Em Hegel (apud ARANTES, 1988) surge, portanto, outra percepção de poder, imbuída de positividade fundadora da civilização.

O dilema entre valores individuais e coletivos, entre espírito e matéria é muito antigo na filosofia. Coube a Hegel (apud ARANTES, 1988) propor uma forma de superação do impasse, ao afirmar que o indivíduo é espírito e matéria, tem necessidades como indivíduo e também necessita do grupo, ao qual fará concessões ao longo da vida, equilibrando suas próprias contradições.

Atribui-se a Maquiavel (1973) a proposta de rompimento entre ética e política, no famoso e pouco lido, O Príncipe. Uma interpretação alternativa sugere que o autor não era moralista, isto é, não era normativo, era antes um relator da realidade da política e do poder (BIGNOTTO, 1992). Tendo exercido funções importantes na diplomacia de Florença, sua produção intelectual resultava não só da reflexão, mas também de sua experiência. De qualquer modo, para estudar política, convém não assumir a interpretação popular de maquiavélico como sinônimo de insidioso e cruel.

Identifica-se em Maquiavel a percepção do poder como recurso fundamental para a implementação de um projeto, de um plano de governo. Dito de outra forma, sem poder, um "príncipe" (ou líder) nada pode e seus súditos, ou liderados, estarão à mercê do acaso (fortuna), ou de um tirano. Ao introduzir o tirano como ameaça ao grupo, Maquiavel aponta a fonte da legitimidade do poder do líder: um projeto visando o bem comum, a elevação da vida material e espiritual do grupo. O autor funda, então, a razão de Estado, que tanto horrorizaria Hayek (1977), séculos depois. Na linguagem da teoria das organizações, se a expressão razão de Estado for substituída por objetivos organizacionais, será possível notar a atualidade do florentino do Século XVI.

No campo da ética, Maquiavel (1973) propõe dois níveis para a apreciação do tema, dependendo da posição do indivíduo no grupo, se governante ou governado. O governado deve pautar-se pela moral pública, leia-se, respeitar as leis, compreender seu papel no grupo, contribuindo para o objetivo comum, à medida de suas possibilidades.

O governante tem sob sua responsabilidade a vida do grupo, está sob a força do acaso, e sob o risco de outros governantes interessados em derrubá- 
lo de sua posição. O líder tem governabilidade (MATUS, 1995) apenas sobre sua virtude, suas competências individuais as quais deve utilizar para tirar proveito da fortuna e para se manter no poder, sem o qual, não haverá bem comum. Portanto, sua ética e moral pautam-se pela relativização entre ações e resultados obtidos em benefício dos liderados.

Os limites entre o tipo de ação do governante e o resultado obtido são dados pela cultura de cada povo e, também, pela lei. O limite final é a tirania, compreendida como o exercício do poder descolado do bem coletivo. Maquiavel não sugere um vale tudo para o príncipe, mas antes, o controle legal e social sobre o governante. A luta para manter-se no poder é inevitável, mas não pode consumir todos os recursos do líder, pois o poder é em si o recurso para a realização do projeto. Porém, o líder que descuidar da luta para se manter enquanto tal estará fadado ao fracasso, juntamente com seu ideário. Por todos esses motivos, a ética do governante não pode ser a mesma dos governados.

Ainda em Maquiavel há a percepção da importância da cultura na determinação das formas de governar, ou, dos "estilos de liderança". Maquiavel execrava a cultura judaico-cristã de sua época, estruturada sobre a humildade (e fundamentalmente, do "não matarás"). Em contrapartida, lamentava a perda do ideário greco-romano do passado florentino, cuja virtude máxima era a coragem. Questionava-se sobre as reais possibilidades de construção de um Estado autônomo quando a moral reinante condenava a bravura e, portanto, cerceava as ações do príncipe, tentando impor-lhe um código moral piedoso, inadequado a sua condição de governante.

Há vários elementos importantes em Maquiavel para a reflexão sobre liderança. Primeiro, a positividade do poder como recurso para realizar um projeto - o senso comum reduz o poder a sua dimensão de tirania. Segundo, o poder só se legitima - e se sustenta - quando exercido em prol do bem comum. Terceiro, há liderados e líderes, funções e papéis diferentes. Quarto, o poder é passível de contestação, é permanentemente ameaçado, obrigando o líder a consumir parte do seu tempo e energia para conservá-lo.

Não se deve perder de vista que Maquiavel era um homem de seu tempo, escrevendo para governantes de seu tempo, tendo por objetivo contribuir para formação de um Estado autônomo, ou seja, tinha por horizonte um objetivo prático e estruturado. Ao recuperar sua obra à luz das necessidades dos líderes inseridos na sociedade ocidental do Século XXI, parte das reflexões contidas em $O$ príncipe perderam o fundamento, pois, de acordo com os 
valores da nossa sociedade, são imorais e ilegais. Cabe a cada um de nós, autores, selecionar as contribuições pertinentes, ampliando nossa capacidade de compreensão e ação.

Ressalta-se o quanto as possíveis contribuições de Maquiavel estão distantes das análises dos traços de personalidade, do líder voltado para tarefa ou pessoas, do coachting, etc. No entanto, provavelmente, um líder reconheceria o ambiente descrito por Maquiavel e prestaria atenção ao seu diagnóstico sobre cultura e clima nas esferas do poder.

Dentro dessa mesma linha teórica de Maquiavel, defende-se a positividade do poder, e influenciado por ele, há outro pensador, Antônio Gramsci (1992), intelectual comunista da primeira metade do Século XX. Foi contemporâneo de Lenin, Stalin e Mussolini. Mussolini manteve Gramsci no cárcere por 20 anos e, paradoxalmente, pode tê-lo salvado de ser executado por Stalin, tal como aconteceu a Trotsky e todas as lideranças leninistas nos anos de 1930 (MONTEFIORI, 2006).

A preocupação primeira de Gramsci era organizar o partido comunista italiano. Assim como Maquiavel, ele tinha objetivos concretos, com metas e estratégias - a exemplo de qualquer executivo do Século XXI. Assim como Maquiavel, precisou lidar com as tensões entre objetivos privados e coletivos, ideais e condutas individualistas versus ideais e condutas coletivas ou comunistas.

Relativamente ao individualismo, Gramsci considerava-o expressão de um Estado pré-hobbesiano, qualificando-o de "apoliticismo animalesco", "origem do clientelismo" e da corrupção (GRAMSCI 1992, p. 18). Assim como Maquiavel, a busca pela obtenção e permanência no poder só se justificava em nome de um projeto de bem-estar coletivo, que libertasse as massas do jugo das leis e da cultura burguesas. O poder supõe, portanto, a existência de governantes e de governados, exige preparo especial dos governantes e a obediência dos governados. Em tempo: obediência é concordar com argumentos racionais, e só é obtida quando os governantes compartilham as informações e as decisões. Daí deriva a ideia de disciplina: "relação contínua entre governados e governantes, freio ao voluntarismo, calcada na legitimidade do governante" (GRAMSCI, 1992, p. 143). E sobre liderança, escreve, o líder é o elemento de coesão que centraliza o objetivo comum, tem como funções articular as potencialidades do grupo, controlar e exercer autoridade, e formar seus sucessores. Quanto às características pessoais, destaca o caráter (resistência aos apelos fúteis), a honra (vontade para 
sustentar novas ideias) e a dignidade (consistência em lutar por um fim superior).

Cotejando esse autor com as teorias sobre liderança, pode-se encontrar pontos em comum tanto nas escolas relacionadas aos traços de personalidade, quanto às contingenciais (a importância da visão partilhada, da participação do grupo nas decisões, da cultura). Não há, porém, análises excludentes, do tipo autoridade ou motivação, disciplina ou decisão compartilhada, não há, principalmente, receio em lidar com o poder, pois sua legitimidade é dada pelo interesse do grupo.

Michel Foucault (1995), pensador francês da segunda metade de Século XX, impôs-se a tarefa de identificar a genealogia do poder, entendida como a história, a explicação oficial e os contextos. Ao iniciar a tarefa, Foucault compreende imediatamente a natureza interdisciplinar do objeto, escolhendo como método a articulação de vários saberes - dito de outra forma, não é possível abarcar a tarefa de estudar o poder na perspectiva de um único saber estruturado, seja a teoria política, a psicanalítica, ou a econômica, etc. Ao lidar com o estudo do poder na perspectiva interdisciplinar, logo adverte seu leitor da impossibilidade de se construir uma teoria geral do poder e admite que não há como identificar sua natureza, essência ou características universais.

Não existe algo unitário e global chamado poder, mas [...] formas díspares, heterogêneas, em constante transformação. [...] não é objeto natural, uma coisa: é prática social, constituída historicamente (FOUCAULT, 1995, p. X).

Sendo prática constituída historicamente, suas formas são infinitas e serão modificadas tantas vezes quantas os contextos forem modificados. Por exemplo, o relógio de ponto já foi prática eficaz de controlar a produtividade do trabalho quando o setor dinâmico da economia era a indústria; sabemos que com a maior importância relativa do setor de serviços, o controle das horas trabalhadas não é necessariamente a forma adequada de medir produtividade. É, portanto, impossível estabelecer que o controle do tempo seja uma forma universal de exercer o poder.

Não é igualmente possível criar uma taxonomia de poder, prática social de infinita variedade, descontínua e tensa. Mas é possível identificá-lo: é algo que se exerce e se efetua, que funciona e que está presente nas instituições, nas leis, nos saberes e na relação "microfísica" entre pessoas. As instituições 
e as leis podem ser destruídas, mas as práticas sociais fundadoras do poder serão reconstruídas, imanentes que são à condição humana. O poder é simultaneamente central e periférico, funciona porque é controle, e seu objeto final é o corpo do indivíduo.

A leitura de Foucault sugere a causa do campo conceitual da liderança ser, até hoje, de difícil delimitação. Se liderança é também uma das formas de exercício de poder, se esse, pela sua natureza, não se sujeita à classificação quanto à forma, como classificar estilos de liderança, de foco, etc.? A grande dificuldade teórica das taxonomias da liderança é ser tão ampla que acaba perdendo a característica de conceito (que impõe, obrigatoriamente, um limite de descrição da realidade, ou não seria um conceito), ou, tão restrita, que não dá conta da realidade. A teoria da liderança contingencial tenta abordar esse impasse, buscando um conceito flexível o suficiente para se adaptar à realidade, porém, retorna ao problema conceitual de origem, estoura o conceito ao sugerir que todos podem ser líderes ou liderados, dependendo da situação. A prática e a reflexão políticas de Maquiavel e Gramsci destroem essa possibilidade, pois há significativas diferenças entre os valores, as características, as práticas, os papéis e as responsabilidades dos líderes e dos liderados.

No cotidiano das organizações do Século XXI, as ações de capacitação, promoção e remuneração são orientadas para diferenciar líderes de liderados, subalternos de postos gerenciais. O incentivo da liderança em todos os níveis, à luz da ciência política e da experiência, pode significar: 1) confusão teórica entre liderança e motivação (há poucos líderes, mas todos profissionais deveriam ser motivados); 2) tentativa de despolitizar as relações de trabalho, na linha de que não há mais funcionários, mas "colaboradores"; 3) tentativa de estimular a ultracompetição entre as pessoas, todos lutando contra todos, pelo papel de líder.

No universo foucaultiano, a mecânica do controle é a permissão ou proibição para gestos, atitudes, comportamentos, hábitos, discursos, movimentos. Nas organizações, muitas têm sido as formas de se exercer o controle, dos tempos e métodos de Fayol à constituição da cultura (HELOANI, 2003). O controle é a capacidade de vigiar e punir, ou, em linguagem mais próxima das organizações, de determinar objetivos, de acompanhar, de distribuir recompensas ou punições. O controle impõe à disciplina uma técnica, um todo sobre o corpo, a organização do tempo, do movimento e do espaço de cada um de nós. 
O poder é dominação e repressão, mas também é formador, por meio da disciplina, da singularidade dos indivíduos e, assim, é eficácia produtiva, riqueza estratégica e positividade. Sendo dominação, gera resistência e movimentos de contrapoder, cujo objetivo é passar de dominado a dominador. Sendo relação social entre pessoas, suas formas variarão na medida em que variarem as pessoas e os contextos, infinitamente.

A obra de Foucault (1995) é marcada pela influência do marxismo e da psicanálise - um foco original, contemplado o indivíduo e a sociedade historicamente determinada. A prática do poder é imanente ao humano, mas suas formas são dadas pelas circunstâncias; se, para Sartre (2002), estamos condenados à liberdade, para Foucault (1995), estamos condenados a exercer e sofrer o poder, sem regras naturais de equivalência (o dominado não domina seu dominador, domina outro, em outro contexto, sob outras formas). O poder é carregado de positividade e negatividade, dependendo da finalidade e da forma como é exercido. O poder de um pai ao obrigar o filho a frequentar a escola é considerado positivo em nossa sociedade, o poder de matar alguém quando se possui uma arma de fogo, é considerado crime.

Assim como em Maquiavel (1973) e em Gramsci (1992), para Foucault, o poder é recurso para a construção do que quer que seja, irremediavelmente, associado ao controle e à disciplina. E disciplina é também autodisciplina, originada na subjetividade já marcada pela longa história de submissão e dominação de cada pessoa. Tanto o dominador quanto o dominado desenvolvem algum grau de autodisciplina. O sujeito individual ou coletivo pode se submeter a um policial, a uma lei, aos valores de sua cultura, disciplinando o próprio corpo; pode dominar por meio da lei, dos valores, da cultura, impondo disciplinas.

\section{Considerações Finais}

O exame de parte da obra de Maquiavel (1973), Gramsci (1992), Foucault (1995) e de Hayek (1977) levanta pontos relevantes para o debate sobre liderança.

Os três primeiros autores trazem à tona a positividade do poder, condição fundamental, ainda que não exclusiva, para a realização de qualquer projeto: aumentar as vendas, guiar a organização durante a mudança $e$ incrementar a produtividade do trabalho. O poder é um recurso tão importante 
nas organizações (ainda que não reconhecido), que todas as recomendações sobre a implementação de novos modelos de gestão, do velho total quality management ao balance scorecard, são enfáticas ao ressaltarem a importância da direção na assunção dos mesmos. Dito de outra forma, sem poder, como implementar o que quer se seja nas organizações?

O líder não deve temer o poder, ou titubear em admitir desejá-lo e exercê-lo - se concordar-se minimamente com Foucault, não há como evitar exercer e sofrer o poder. E, dado que o poder só se configura como relação entre pessoas, aprender a ser liderado é tão necessário quanto aprender a liderar. No entanto, as organizações investem na formação em liderança e deixam à cultura, em grande medida não controlável, a função de ensinar como ser liderado.

As abordagens teóricas da liderança definidas, enquanto voltada à indução da mudança nas organizações (e seu correlato, do gerente como controlador de processos), observam que ambos, gerentes e líderes, são igualmente necessários e importantes para o sucesso da organização. Não é possível discordar de tal afirmação, porém, dada a hegemonia dos valores individualistas na sociedade capitalista, como não admitir o conteúdo pejorativo da posição de liderado ou de mero gerente de processo? A quase totalidade dos cursos de pós-graduação lato senso, e até mesmo algumas escolas da Educação Básica prometem como benefício formar líderes e não liderados. A organização sofre, portanto, de uma contradição (entre tantas outras): precisa estimular a formação de lideranças e, ao mesmo tempo, precisa de pessoas que, contrariando o valor dominante, concordem em ser lideradas.

As várias classificações presentes nas teorias da liderança procuram encontrar a forma mais eficaz de exercer a liderança. Os autores da política aqui examinados sugerem que a eficácia do poder dependerá dos objetivos, dos recursos disponíveis (inclusive os do oponente) e das circunstâncias. De acordo com Maquiavel (1973), também da fortuna. Foucault (1995) acrescentaria que, sendo inútil procurar classificar as formas de exercer o poder, melhor seria ajudar as pessoas a desenvolver autodisciplina para controlar o voluntarismo, e aprender a escolher estratégias de acordo com as circunstâncias.

Retomando os temas propostos pela liderança contingencial, é exequível um único indivíduo ser capaz de variar tantas vezes as estratégias (condutas) quantas a situação exigir? Afinal, o indivíduo, fruto da disciplina imposta pelas relações de poder, construiu seu estilo particular. O poder implica em um conjunto básico de atitudes: ser cruel, se necessário (MAQUIAVEL, 1973), 
entenda-se, demitir, fechar uma fábrica, frustrar expectativas de bônus, etc.; não esperar o respeito do grupo em qualquer circunstância, que esquece rapidamente o bem recebido; ter consciência da importância da própria imagem e das ações necessárias para mantê-la (porque a percepção dos liderados pode ser diferente da autopercepção do líder); estar preparado para compreender sua função simbólica e, principalmente, para seu grau de responsabilidade.

Não há líder sem um projeto, as pessoas só se deixarão liderar enquanto virem nisso uma fonte de benefícios, elas não o seguirão sem um objetivo adequado a todos (MAQUIAVEL, 1973). Se a cultura da organização for demasiadamente individualista, se os liderados não se pautarem pela moralidade pública, será muito difícil liderar, pois muito tempo e recursos serão consumidos para mostrar às pessoas o retrocesso de se pretenderem superiores aos interesses coletivos.

O líder sofrerá, diuturnamente, os ataques de outros líderes ou candidatos, seja pelos interesses individuais ameaçados, seja pelos projetos de poder dos adversários; consumirá tempo e energia para continuar líder e deverá encontrar formas de vencer as guerras. A ameaça objetiva ao líder é constante, além do que se possa chamar de administração de conflitos. Em síntese, é razoável pensar que há pessoas que não sabem, não podem ou não querem viver as experiências características do poder.

A leitura de Gramsci (1992) contribui para a prática da organização das equipes. Em primeiro lugar, o líder deve compreender as aspirações de seu tempo e das pessoas do grupo, construindo coletivamente um plano para a superação dos limites atuais. Os líderes são poucos, os liderados são muitos, mas todos têm papéis imprescindíveis - os líderes não são, necessariamente, mais importantes, nada fariam sem um grupo coeso e disciplinado, pouco fazem onde impere a cultura individualista, origem da corrupção e do clientelismo. O projeto é mais importante, sempre, e cabe ao líder preparar seu sucessor, preparar os próximos líderes, e preparar-se para deixar a posição quando for a hora.

Nos limites da bibliografia pesquisada para o presente artigo, a principal contribuição de Foucault (1995) é ajudar a afastar do líder o medo do exercício do poder. Somos todos objetos do poder, sofremos as ações desse poder sob muitas formas, sob outros líderes, individuais ou coletivos. O líder não terá poder se não for capaz de controlar, de acompanhar os processos, as pessoas, os resultados, e de distribuir recompensas e punições. 
A expressão influenciar, usada pela quase totalidade dos autores originários da psicologia social para definir o ato de liderar, pode ser utilizada como sinônimo de controlar, no universo teórico de Foucault. A influência de um sobre outrem só é relevante para a organização na medida em que leva o segundo a agir; se um pode levar o outro a agir, é porque o primeiro tem algum recurso de poder, escudado em alguma instituição (o saber, por exemplo), e capaz de exercer o controle. Nos últimos momentos da Segunda Guerra Mundial, durante a Conferência de Ialta, em 1945, Stalin, Roosevelt e Churchil decidiam a divisão geopolítica do mundo. Churchil sugeriu aos seus pares fazer do papa um aliado, ao que Stalin, opondo-se, respondeu na forma de gracejo: "[...] como os senhores sabem, a guerra é travada com soldados, canhões, tanques. Quantas divisões tem o papa? Se ele nos contar [...] que se torne nosso aliado" (MONTEFIORE, 2006, p. 535).

Ora, o papa não possuía os recursos de poder relevantes na discussão sobre a divisão do mundo, não obstante, possui muitos outros recursos - $e$, portanto, poder - em várias outras situações, como por exemplo, nas discussões sobre a conduta adequada dos católicos. A capacidade do pontífice de influenciar as pessoas é o mesmo que seu poder de levar as pessoas a agir de acordo com regras estabelecidas pela igreja, $e$ a instituição provedora $e$ legitimadora de seu poder é a religião, ou antes, a fé dos católicos em seu credo e igreja.

Foucault ensina que o poder se materializa no controle (vigiar, punir ou premiar), e o poder é a capacidade de levar alguém a agir, é a relação contextualizada entre pessoas. Se as afirmações do autor são pertinentes, a liderança descolada de alguma forma de controle ou não se define como tal, ou não se sustenta por muito tempo. Um indivíduo pode não ocupar o maior cargo hierárquico da organização, não obstante, ser líder de seu grupo, como a experiência comprova tantas vezes. Um técnico de grande reconhecimento pode exercer a liderança e decidir a melhor forma de realizar um projeto. $\mathrm{O}$ grupo o seguirá porque lhe reconhece a competência técnica e teme o erro de fazer diferente de sua orientação, ou prefere o conforto de não precisar pensar sobre o projeto. Em tal situação, o recurso de poder é o saber, legitimado socialmente pela grande importância que nossa cultura dá ao conhecimento, a punição é o risco de errar, geradora de autodisciplina, e a recompensa é o conforto de não precisar criar novas formas para o trabalho.

A experiência também mostra o quão frágil é a liderança sem formas mais diretas de controle, tais como os sistemas gerenciais de informação, ou 
de punir, tal como demitir, rebaixar, denunciar, isolar do grupo, etc. Se cabe ao líder motivar (KOUZES; POSNER, 2003), ou criar condições de automotivação para o grupo (BERGAMINI, 1994), cabe também a reflexão sobre o quanto o líder pode obter resultados exclusivamente por meio da motivação. Por mais que o indivíduo esteja comprometido com a moral cívica (BIGNOTO, 1992), ou com a necessidade de atingir os objetivos da organização, Maquiavel não descarta a importância da lei para levá-lo a cumprir o estabelecido. Nos exércitos em guerra, talvez essa seja a situação na qual a atuação do líder pode levar literalmente à vida ou à morte, os soldados são tão emulados e motivados, quanto ameaçados com a corte marcial, como a história dos grandes combates registra. Nas organizações atuais as pessoas não são ameaçadas de morte, mas sentem a pressão da perda de posição, do emprego, do bônus, etc. E o líder não está desconectado de todas as formas de controle, punição e recompensas próprias do mundo dos negócios.

O controle pode ser exercido de infinitas formas, inclusive por meio da cultura, resultando na constituição da autodisciplina. Os liderados não são inertes, não seguirão o líder alegremente, em qualquer condição, ao contrário, sempre oferecerão algum grau de resistência e reações de contrapoder. Tal qual sugerido por Maquiavel (1973), o líder deve estar preparado para tais disputas, mantendo-se em eterna vigilância. Não há vácuo de poder nas organizações, se alguém desiste de assumi-lo, outrem o fará. E urge evitar a profecia de Hayek (1977), deixando que os piores assumam.

A grande questão proposta por Hayek (1977) é: como evitar que o bem comum acoberte interesses particulares? Como evitar o risco do poder transformar-se em tirania (para usar a expressão nos termos de Maquiavel)? Como evitar a degradação do indivíduo sob o jugo da dominação sobre o corpo e a consciência, ou no exercício da dominação? Como as pessoas serão felizes sob dominação?

Hayek é um autor preterido por muitas correntes intelectuais, em virtude de sua assumida posição de destaque no pensamento neoliberal. No entanto, ele levanta uma questão-chave para o tema do poder na sociedade e, portanto, nas organizações: como evitar que o poder seja apenas coerção e dominação? Maquiavel tratou da lei, da cultura e da legitimidade do projeto, Gramsci invocou a superioridade dos valores coletivos sobre os individuais e da democratização do debate antes da decisão. 
Se o poder não é em si, positivo ou negativo, se os objetivos e as formas lhe conferem positividade ou negatividade, devemos pensar sobre os dois últimos elementos quando tratamos da liderança nas organizações. Um campo particular da filosofia, a ética, contribui para a reflexão.

Esse tema, ética, é ainda mais amplo e controverso do que liderança. Foge aos objetivos desse artigo levar adiante tal debate. Assumindo o risco de simplificar o complexo, pautando-se pela tradição hegeliana, propõe-se diferenciar ética e moral. A ética é a ciência do móvel da conduta humana, $e$ o móvel da conduta humana é o desejo ou vontade de sobreviver, ou ainda, o prazer; é a realização do bem em realidades históricas, a saber, a família, a sociedade civil e o Estado. A moral é vontade subjetiva, é a dimensão individual do desejo de sobrevivência ou no, limite, do prazer (ABBAGNANO, 1999; HEGEL, 1997).

O líder exercerá o poder legítimo se suas ações tiverem sofrido previamente o crivo da ética e, portanto, seus objetivos poderão ser explícitos ao grupo. Não haverá objetivos ocultos, não haverá manipulação de informações e de propósitos. Porém, copiando Maquiavel, a ética por si não dá conta de proteger os grupos da tirania (BIGNOTO, 1992), é preciso que as organizações tenham regras claras para impedir desmandos. A repetição da conduta baseada na ética funda a moral do líder, dá-lhe integridade e coerência nas ações, permitindo ao grupo desenvolver relações de confiança. Constituir sistemas de gestão e de decisão orientados pela ética é ir muito além da assunção do politicamente correto e seus modismos correlatos. O clichê, repetitivo e superficial, propõe um padrão de discurso que precisamente, possa evitar o pensar sobre a ética e a moral das práticas e projetos. No mundo do clichê, uma organização pode gastar dinheiro com alguma ação filantrópica e, ao mesmo tempo, adotar estratégias de marketing nas quais o concorrente é explicitamente denegrido, pois a chamada responsabilidade social está na ordem do dia, enquanto que campanhas de marketing desqualificando o concorrente são tão somente "agressivas". A ausência da reflexão protege as condutas da crítica.

Em síntese, vários problemas conceituais e práticos do campo teórico da liderança podem ter outras perspectivas quando cotejados pela teoria política. 


\section{Power and Leadership: the contributions of Maquiavel, Gramsci, Hayek and Foucault}

\section{Abstract}

Leadership is an ample field in the universe of the organizational behavior. The concepts are problematic, in the direction of the delimitation of the study object. Most of literature originates in social psychology, the theory politics little is explored in the construction of the concepts. Contributions of the deriving authors of social psychology, when translated for the great public they had taken the dissemination of stereotype and "to do", marked for the politically correct call and for the no politics of the subject. Objective: to show that science politics can extend the debate, considering the study of the relations between being able and leadership in the organizations. Methodology: bibliographical, compatible revision with the theoretical assay. Conclusions: science politics allows to define leadership as exercise of power in the organizations, skirting the conceptual problem of the subject; power does not have negative connotation or positive, such judgments respect to the forms and objectives of the power; to exert the power is a contingency of the leadership.

Key-words: Organizacional behavior. Leadership. Power.

\section{Referências}

ABBagnanO, N. Dicionário de filosofia. São Paulo: Martins Fontes, 1999.

ARANTES, P. E. (Pref.) Hegel. São Paulo: Abril, 1988. Col. Os Pensadores, V. 1.

BERGAMINI. C. W. Liderança: administração do sentido. 3. Tiragem. São Paulo: Atlas, 1994.

O líder eficaz. São Paulo: Atlas, 2002.

BIGNOTO, N. As fronteiras da ética: Maquiavel. In: NOVAES, A. (Org.) Ética. São Paulo: Cia.das Letras, 1992.

DANTAS, M. Valor-trabalho e valor informação. Revista Transinformação, v. 8, n. 1. jan./abr. Campinas - PUCCAMP. 1996. 
DOWBOR, l. O que acontece com o trabalho? São Paulo: SENAC, 2002. FOUCAULT, M. Microfísica do poder. 11. ed. Rio de Janeiro: Graal, 1995.

GRAMSCI. A. Obras escolhidas. 2. ed. São Paulo: Brasiliense, 1992.

HEGEL, G. W. F. Princípios da filosofia do direito. São Paulo: Martins Fontes, 1997.

HERSEY, P. BLANCHAR, K. Psicologia para administradores: a teoria e as técnicas da liderança situacional. São Paulo: EPU, 1986.

HAYEK, F. O caminho da servidão. 4. ed. Rio de Janeiro: Instituto Liberal, 1987.

HELOANI, R. Gestão e organização no capitalismo globalizado: história da manipulação psicológica no mundo do trabalho. São Paulo: Atlas, 2003.

JUNG, K. G. Fundamentos de psicologia analítica. 4. ed. Petrópolis: Vozes, 1987.

KOTTER, J. P. A force for change: how leadership differ from management. New York: Free Press, 1990.

KOUZES, J.; POSNER, B. P. O desafio da liderança. 3. ed. Rio de Janeiro: Campus, 2003.

KUHN,T. A estrutura das revoluções cientìficas. 6. ed. São Paulo: Perspectiva, 2003.

LAKATOS, I. O falseamento e a metodologia dos programas de pesquisa científica. In: LAKATOS, I. MUSGRAVE, A. (Org.) A crítica e o desenvolvimento do conhecimento. São Paulo: Cultrix, 1983.

MAQUiAVEl, N. O Príncipe. 1. ed. São Paulo: Abril, 1973. Col. Os Pensadores.

MATURANA, H.; VARELLA, F. El arbol del conocimiento. Santiago de Chile: Hachete, 1997.

MATUS, C. Chinpanze, maquiavelli y Gandhy: estrategias políticas. 1. ed. Caracas: Fondo Editorial Altadir, 1995. 
MONTEFIORE, S. S. Stálin: a corte do czar vermelho. São Paulo: Cia. das Letras, 2006.

POPPER, K. A lógica da investigação científica. São Paulo: Abril, 1980. Col. Os Pensadores.

PRIGOGINE, I. STENGERS, I. A nova aliança. Brasília: UNB, 1991.

ROBBINS, S. P. Comportamento Organizacional. São Paulo: Prentice Hall, 2005.

SARTRE, J. P. O ser e o nada. Petrópolis; Vozes, 2002.

TOOD, E. A ilusão econômica: ensaios sobre a estagnação das sociedades desenvolvidas. Rio de Janeiro: Bertrand Brasil, 1999. 